\title{
EVALUATION AS AN INDIVIDUAL AND ORGANIZATIONAL LEARNING PROCESS THE RESEARCH EXPERIENCE OF THE EUROPEAN PROJECT- EDUEVAL
}

\author{
Stefania Ulivieri Stiozzi \\ University of Milan-Bicocca, Italy
}

\begin{abstract}
Adult education services - in Italy and Europe - are strongly in need of an advanced evaluation culture. How may we create the necessary conditions for the educational value of high-quality evaluation to be recognized? What does "evaluate" mean for managersof adult education staff? What organizational and relational dimensions are called into play by evaluation practices? How should evaluation be carried out in training groups, occupational skills programmesand in services providing care for fragile adult subjects? What knowledge disciplines should be included in the education and training profile of evaluators who wish to bring mindfulness and rigour to the implementation of their role? This paper examines the aims and instruments adopted by the European project EDUEVAL, presenting the results of a qualitative study conducted with a purposive sample of official and unofficial evaluators in Italian adult education contexts, and exploring the educational and learning dispositives required to make evaluation a practice motivating and fostering highquality educational work within an organization.
\end{abstract}

Keywords: affect, education, training, group, organization, evaluation.

\section{Introduction: the European background to the EDUEVAL project}

It is now widely accepted by both academics and politicians that adult education has a key role to play in bringing to light and transforming social conditions in Western societies andin supporting new visions of inclusionand intercultural democratization in Europe over the coming decades (Buiskool, Broek, 2014) EU policies have long identified the adult education sector as a potential driver of innovation, with the power to revitalize the jobs market, in the current conditions of serious instability in Europe. The educational dimension assumes even greater importance in light of the profound economic crisis that has affected the European economy over the past twenty years.

A recent study, (Motschilning, 2014) conducted in $19 \mathrm{EU}$ and non-EU countries, shows that investments in adult education yield returns for the economy as well as for individuals and society. The analysis suggests that adult learning has a crucial contribution to make to the future of the EU, being even more critical to attaining innovation targets than secondary education systems. The research pointed up, for example, that on-the-job learning, which addresses the complexity of the tasks, is the leading factor in innovation outcomes.

The EDUEVAL project explores the theme of evaluating the work of adult education staff, by comparing the models and practices of evaluation in the 
countries of the project partners (Italy, Spain, Greece, Latvia and Poland). Evaluating the work of a team engaged in professional skills training or in the care and rehabilitation of adults in difficulty, is a key challenge today. Evaluating means looks for new ways of improving the quality of educational interventions, of promoting new work models and strategies, and of allowing educational sectors otherwise at risk of conforming to excessively narrow and inadequately problematized perspectives, to develop new horizons that are innovative and open to designing interventions to cater for the new needs of a continuously evolving social fabric. The leading aim of the EDUEVAL project is to draw up a European-wide evaluator profile, via the definition of an educational/training pathway and professional guidelines for those wishing to enter thisdelicateprofession, in an era in which worker mobility has become a necessity.

Indeed, although evaluation is a key focus of interest within both the international scientific debate (Barbier, 1985; Bezzi 2001, 2007; Patton,2010) and the organizations called upon to account for their work and to measure the impact of their interventions on the adult learner population, it is more difficult to pin down the precise competences and professional profile required by an evaluator or the processes of cultural transformation set off by evaluation practices within organizations whose role is to safeguard, promote and provide care for adults in conditions of temporary or permanent disadvantage. If we are to go beyond viewing evaluation as a merely formal act of certifying the quality of a service, we cannot but explore the process that this practice sets off within educational services and reflect on the changes in their educational cultures that it provokes.

We are particularly interested in the theme of evaluation because, in our role as educational scientists, getting value from processes of evaluating the work of educational staff, means intervening to enhance the learning processes of the professional figures involved, and investingfrom a future-oriented perspective, in the knowledge and competence available within an organization in the area of education/training, in order to reinforce its identity and enhance its ability to define and transform its own internal work processes.

In order to meet this objective, we investigated - by means of a recently concluded qualitative phase of our research conducted in all the partner countries - the multiple representations of evaluation held by a purposive sample of official and unofficial evaluators, in order to advance our understanding of how such representations shape - within diverse epistemological frameworks and models of intervention-the evaluation practices implemented across the different countries. 


\section{The Research Plan: goals and methodology}

Our research plan was outlined in the following levels, each one functional for the achievement of specific goals yet integrated in connection with the above specified purposes:

1. A desk-research aiming to explore and systematize in a critical way the national and international literature regarding the topic of the evaluation in adult education, finalized to let its theories and most qualified and current scientific models emerge. Furthermore, the research has gone over the evolution of the regulatory plansin the last decades as regards to the lawsgoverning the sector of adults'education and has carried out a deepanalysis of the evolution of European policies in this area.

2. A qualitative and «micro-pedagogical» research (Demetrio,1992) carried out with a selected sample of twenty official and non official evaluators who act on the Italian territory and especially in two of the widest and most representative regions (Lombardy and Puglia), with whom we conducted several semi-structured interviews. Our goal has been to investigate with a «clinical» approach ((Massa, 1993; Riva, 2004) to the texts analysis, the plaiting between cultural meanings and representations of the evaluation, starting from the point of view and from the professional work experience of each singleevaluator involved, in order to highlight similarities and differences from the comparative analysis of the texts produced, of which this article offers a critical synthesis;

3. A «partecipatory action research» phase (Reason, 1995) achieved through a five days residential workshop, that took place in Crete last July. Professionals active in the evaluation area, coming from the various different territorial realities represented in the project, have worked side by side with the researchers to develop a shared knowledge, through acostructionist and cooperative research approach. Each Country has presented one case- study that has been the subject of a critical/reflective work (Schön, 1993) realized among the transnational groups. Through the arrangement of a work setting oriented to the exchange of experiences, it has been possible to reflect on different epistemologies that direct the evaluation practises in the various contests and to start an interesting process of intercultural dialogue aimed at goals of transformative learning.

\section{The key role of the educator from the European perspective}

The emerging strategic vision of the European Union is that of an adult who is constantly engaged in growth and development, and who is capable, via targeted educational and self-educational pathways, of constructing new 
insights, new mentalities and new existential and professional instruments for exercising his/her role as a responsible citizen, in a society in which democracy increasingly appears to be an outcome dependent on adults' increasing involvement in processes of mindful selection and choice. Attaining such objectives implies revisiting society's fundamental values, in light of the contribution that each individual citizen can make to the transformation of the social and cultural fabric (Orefice, 2005). The idea is for adult education to become one of the most advanced sectors within a society that aims to:

Encourage ecologically sustainable development, with a view to promoting democracy, justice, gender equality, and social, scientific and economic development and to building a world in which violent conflict is replaced by dialogue and a culture of peace based on justice (De Natale, 2006, p.13)

Adult education, furthermore, is the sector devoted to reinforcing the competences of marginalized subjects, by tapping into their residual resources and targeting effective inclusion processes enhancing their quality of life. This specific aspect of adult education makes it the operational arm of an advanced society offering equal education opportunities to all its citizens, independently of initial conditions of disadvantage, and actively implementing educational pathways to develop the autonomy and inclusion of all community members. Respect for diversity, tolerance and promoting difference thus become the key principles of an authentically intercultural society, which is capable of responding to new educational and care requirements emerging from a social fabric that is increasingly complex and stratified.

Viewed from this perspective, the cultural and social role of educators becomes critically important (Tramma, 2008). As an occupational category, educators, above all others, appear to be called to rethink their own cultural assumptions and to develop ongoing critical reflection on the educational value of their intervention models and practices, precisely because they have been assigned strategic responsibility for embodying the new values in their operational programmes. The cultural role of educators is given by their role as mediators, with the capacity to create new and concrete opportunities for social inclusion for the most fragile categories of adults in a society, which, due to its emphasis on the sophistication of knowledge, runs the risk of increasing the gap between adults who are capable of responding to the challenges of a constantly changing world and oriented towards high levels of performance and competitiveness, and those who, due to different forms of disadvantage, can easily find themselves in even more marginalized situations that diminish, rather than augmenting, their presence and exercising of their rights. It is precisely educators' currently weak professional profile and their daily involvement through their work with the needs of disadvantaged adults, which makethem a key investment priority within the overall effort to promote lifelong learning.

One of the cornerstones of our research project was to generate exchange among educators and trainers froma range of adult education services in order to 
promote the comparison of the different educational perspectives underpinning their models and practices of evaluation. This process took place at a residential workshop in held in Crete in July 2014, with the participation of evaluators from the countries of the research partners, who worked side by side with the research teams to develop a shared knowledge. Following a case-study methodology, transnational discussion groups were set up to reflect on the different epistemologies orienting evaluation practices in the different contexts and to initiate a valuable process of intercultural exchange aimed at attaining transformational learning outcomes.

\section{Examining the paradoxes of evaluation: resources and problem areas identified in relation to the Italian evaluation scene}

The overall situation of education services in Italy today appears to feature contradictions and paradoxes, which must necessarily be taken into account in addressing the theme of evaluation (Benedetti, Donati, Fazioli, Maffeo, 1997; Kanéklin, 2000; Ulivieri Stiozzi, 2015). Our findings suggest, also in light of the comparison with other European contexts, that evaluation practices can function as dispositives that deviate socially-oriented cultures towards purely economic and profit-driven aims. The interview data for our entire sample indicates that evaluation is often subordinated to a key emphasis on the services' economic targets, and that evaluation does not always successfully capture organizational culture or bring to light its limitations and scope for potential change. Defining the quality of an intervention in services which produce immaterial goods is a complex process and an "impossible" task; it is difficult, for example, to establish criteria for evaluating the quality of an educational programme implemented with an adult with disability, without taking into account the many variables characterizing the life of the educational service. How does that particular team work? What is done to support the personal and professional growth of that specific work group? What are the educators' models of care and how do these models interact in the course of planning and evaluating their interventions? What is relationship between the wellbeing of the education staff and that of their clients?

The interviewees in our sample report that the world of education is complex: there is no one right approach and it is not possible to measure an outcome that is valid for all parties. The lack of objectiveness inherent in educational processes is also reflected in differences in the measurement criteria and the perspectives brought to bear on evaluation: education is a highly delicate area, that is challenging to pin down and is in a constant state of flux, such that in a given educational situation the initial aims may be constantly redefined as a function of real-time developments. Because education is a continuous and dynamic process, it is difficult to identify standardized instruments with the power to photograph and monitor such complexity. In such contexts, evaluation 
must necessarily be viewed as a complex dispositive that assesses processes following a systemic logic.

Nonetheless, within a socio-political framework that pushes adult education services to optimize costs and produce objectively measurable outcomes, it may be that the educational knowledge and competence which pervades the daily life of an educational service is sacrificed; evaluation practices often consist of nothing more than a series of procedures and protocols which cut the information to be processed down to the minimum.

Instead of using such instruments with a pre-test function to assist in developing a shared and more exhaustive exploration of the processes implemented, there is a danger that the monitoring of a client's educational programme or of the level of satisfaction with an occupational skills course will be entirely delegated to codified instruments.

The accounts of the evaluators interviewed for our study clearly suggest that evaluation is an act which risks impoverishing educational work by bringing it into line with pre-defined standards and which fosters on the part of educators, often at an unconscious level, a tendency to develop a detached perspective on their work, and the inability to problematize the education contribution being implemented in a given setting:

In the reality of their daily work the educators themselves are so overburdened with everyday routine and contingencies that it is hard to elevate one's thoughts. So many actions are carried out in the educational services and they aren't seen. (M.A.)

In organizational as well as in educational settings, evaluation seems to have become totally proceduralized, an object that almost goes unobserved, hidden by the rules and about which one no longer reasons, one no longer even questions. Things are the way they are. (M.O)

The interviewees agree that evaluation is a dispositive driven by implicit codes that discipline behaviours and orient perspectives towards a superficial interpretation of information, which is often stripped of its historical, dynamic and contextual substrates. The invisible retreats and disappears from sight, leaving in the shadow the entire set of actions, behaviours and meanings that come to life within everyday relational processes in an educational setting.

Educators know, thanks to their training, that the vital core of their work lies in this ability to look beyond appearances and to empathically draw closer to their clients' vision of the world. They know that under the surface there is valuable material towards which they need to train their gaze. They know that educational work is acted out in the presence of oneself and the other, and that this presence is an embodied act of self-revelation, which requires a long time frame and the courage to learn from one's mistakes. They know that a united work group acts as a mirror required to integrate the perspectives of individual educators and to provide affective support to each of them at times of disorientation, doubt and frustration. But how can this dynamic process be 
translated into a product accessible to evaluation? How may evaluation practices be adapted to sustain and value this process of educational growth within a service?

In the contemporary educational context, the risks of a homogenization of perspectives, and of a loss of critical and reflective capacity on the part of those operating in the sector, are concrete and shared by all of our interviewees: the participants in our study all stated that - if evaluation is to become a constellation of practices aimed at promoting processes of innovation - it must have a focus on targeted ongoing training processes for educators.

Transforming the practice of evaluation into a learning dispositive is nonetheless a highly delicate operation for which the whole organization needs to receive specific training: clearly defined criteria and transparent practices must be put into place, but above all, it is critical to co-construct, within each given educational setting, a high-level interpretation of evaluation bases on the ethics of behaviour, and which far from being highly regulated and prescribed, should be the outcome of a process of enquiry and negotiation within the organization.

Being evaluated indeed bears a high cost at the emotional level, particularly when those implementing it are not aware of the deep level at which they are acting, of their implicit power apparatus and of the fact that it elicits powerful emotions linked to the dynamics of personality formation of the individual being appraised:

It is tough because no matter how prepared for it you are, it is always something that touches deep chords that vibrate within us. It is challenging to manage at the relational and hierarchical levels, because those being appraised always tend to try to give a camouflaged image of themselves (S.S)

The evaluators recount that the first component of resistance to evaluation is to be found within the educators themselves, in their personal history and in the defences that they erect in the face of the threat of evaluation, experienced at the outset as an intrusive judgement, as a telluric movement shaking the foundations of their identity, still before those of their professional role.

We have psychoanalysis to thank for having brought to light the close link between our schemes of thought and our interpretation of experience leading us to behave in ways that are often unmediated by mindful or reflective thinking, as well as the unconscious history that formed them beginning in the earliest years of life with identification with our family's cultural models (Ferenczi, 1933; Riva, 1993; Kaës, 2009). An adult's systems of meaning are the outcome of well-established attribution processes, marked by the key experiences, traumas and ruptures scattered along his/her life path. Each of our «perspectives of meaning" forms and selectively delimits our perception, cognition, feelings and disposition, predisposing us to given intentions, expectations and aims». (Mezirow, 2000, p.11). 
The emphasis placed by psychoanalysis on the process of unlearning as a fundamental prerequisite for the development of new learning is critical to our reflection here: any adults who wish to develop new forms of interpretation of the self and of reality, must take on the onerous task of revising the assumptions that have made them as they are, shaking up their own defence systems, shaped by archaic emotions that contributed to their erection and which have to do with the fulfilment of our deepest needs. Becoming open to a new system of attribution of meaning impacts on expectations and unconscious desires, eliciting the emergence of primitive anguish andanxiety that challenge the way in which, since our earliest childhood we have structured our relationship with the process of separating/disidentifying with our "internal objects". (Klein, 1952).

The fear of being judged - expressed in the interview extract just quoted is understandable given the process of revelation of previously unknown areas lit up by evaluation:allowing oneself to be read/interpreted/scrutinized by a colleague or superior is a significant and psychically painful experience; educators who make themselves available to do so must cope with the dismantling of their primary defences and with the pain associated with the professional self-representation which may elicit feelings of inadequacy and poor self-esteen connected with significant past experiences. Given that evaluation brings into focus critical areas of one's work, the appraisee must be given the tools required to modify some of his/her interpretive schemes and tolerate the uncertainty connected with change. Remaining suspended in a place between anguish and hope, in the transitional psychic space of the search for new frameworks of meaning, is not easy if the work group does not provide the individual with a sufficiently stable and welcoming container; then, as pointed out by the evaluators interviewed in the current study, evaluation can generate counterproductive emotional dynamics which take the form of either a strongly resentful attitude with the function of projecting aggressiveness onto the evaluator, or of denial behaviours, often accompanied by passive and depressive states of mind. Evaluation, our informants told us, is a dispositive to be handled with great skill and caution, precisely because, if not properly managed, it can have highly adverse effects on the motivation of individual educators and on the atmosphere of cooperation within the work group. The group or the individual, in turn, can react by setting in motion defensive and counter-transference dynamics, thereby undermining the effectiveness of the evaluation itself. In order to illustrate more powerfully the impact of evaluation on the equilibria regulating the identity of subjects and groups, I would like to draw on the analysis of a self-evaluation process conducted with students in basic training as part of a theoretical-experiential course designed to develop knowledge and skills in the field of educational counselling. During the evaluation phase, these students translated the laborious psychic process of appraisal that they had experienced, into an eloquent image: they depicted an underwater landscape 
slowly rising to the surface and populated with new forms of animal and vegetable life which were still undefined and shapeless, a landscape in which the dense darkness was now and then penetrated by the light of day. During the process of reading/interpreting the image produced by the students, it emerged that their use of this biological metaphor was an allusion to the fact that they had been exposed to a repertoire of new forms of knowledge that had obliged them to profoundly remodel certain of their forms of thinking, in which they had previously connected educational events with those of their own life story.

They had experienced this educational exercise as a form of narration oriented towards the future, which had required them to review their own history with a view to critically questioning the cultural assumptions on which they had previously based their models and theories. The final course evaluation became not only a process of self-evaluation in relation to that one educational experience, but also a far broader process, in which the students evaluated their own competences by analysing their prior educational history from a hermeneutic perspective that involved looking at it from new angles. The new awareness gained was represented by the rays of light that promised to open up new future scenarios but which, for the time being, were not yet quite clear and remained enveloped in a shadow of uncertainty and fear. The group expressed a feeling of being at a critical threshold and moment of transition, in which it was no longer possible to turn back and in which the fresh insights they had acquired needed to be translated into new plans and strategic moves, in order to transform their hitherto shapeless desires into clearer and more defined projects and objectives.

As emphasized by Pellerey this kind of transformational learning process involves a projecting onto the future in which «the consideration of the "possible selves' plays a complex role, a set of subjective future realities that are both desired and feared, of expectations that inhabit our hearts and minds, of dangers glimpsed by each of us, of fears for the future, of aspirations and desires, of ideals and of each of our private and public dreams. [...] A narration of possible or probable future actions, reactions and interactions, of foreseen or feared educational effects, of alternatives to possible defeats or resistances encountered» (Pellerey, p.7)

For a professional team to be equipped to stand up to the effort involved in evaluation, it must receive training in the meta-reflective competence required to learn from one's own and others' mistakes, a competence that is linked to the degree of trust that a group develops over time. It is therefore important, to bring to bear a counselling perspective, to lead the group to have a level of internal cohesion and a degree of psychic flexibility such that evaluation can become learning and both the group and its individual members can have sufficient trust to be able to integrate its effects and implications into their professional roles (Bion, 1972) 
When evaluation processes do not deeply penetrate the cultural fabric of an organization, there is a risk of generating, instead of openness to change, a closed, apathetic and bureaucratic approach on the part of the work group, which is reflected in high levels of burnout, voluntary resignations or a drop in productivity. The general atmosphere in the work place may be adversely affected: levels of internal conflict and behind-the-scenes power struggles increase and an excessive competitiveness is generated that undermines relationships and causes quality of work to disimprove.

It follows that conducting evaluations means taking the relationship between evaluation and values seriously; indeed, evaluation practices that have been artificially stripped of the values that inevitably orient it and condition their outcomes, are purely rhetorical constructions, which risk being used as a disciplinary dispositive that jeopardizes organizational wellbeing and the internal cohesion of work groups.

\section{Conclusions What kind of training does the evaluator require?}

All the interviewees made interesting observations on the theme of the evaluator's responsibilities, training and the need for someone who is in charge of such a delicate process to be highly qualified and to have a rich set of skills in keeping with their role. In general, our informants reported a reality currently dominated by a lack of rigour and strong variability: many of those with responsibility for conducting appraisals are improvised evaluators and do not have the training or the professional maturity required to carry out their work to a satisfactory standard.

According to the participants in our research, one of the major challenges is posed by the lack of an advanced evaluation culture and of a specific training background to prepare those who conduct evaluations as their daily work, to reflect on the profound consequences of their actions and to be familiar with the emotional reactions elicited by their practice. As one manager stated:

In order to be an effective evaluator you need to suspend your judgement, to stand back from it, because otherwise the act of evaluation will necessarily be contaminated by your own prejudices. And that is not effective evaluation. In my view, evaluation is an act that enables practices to be transformed into new knowledge (S.S)

However, such an approach is unlikely to develop from a personal inclination but requires constant training and a level of self-knowledge that can only be attained thanks to specific educational dispositives promoting listening and self-listening abilities, and teaching how to recognize and manage emotions, in highly stressful professional situations.

The evaluation process implies a constant focus, on the part of those implementing it, on the attempt to "measure" their communications and 
modulate their interventions because there are relationships at stake as well as the safeguarding of an equilibrium that is functionally to the group being able to successfully complete its work. It demands of those who practice it, strong observation and listening skills for integrating visible and invisible aspects of the personality and professional style of the appraisee, the ability to mediate and to provide feedback designed to draw out the resources of the staff being evaluated and enhance their performance:

Evaluating demands observation and listening at a number of different levels because I think that you can do evaluation well if you are able to identify the various levels at which people express themselves through verbal and nonverbal communication; the emotional level is key, as is the ability to manage situations at the stressful emotional level as well, and then the capacity to empathically connect with people and the willingness not to make snap judgements. One also evaluates people's personal characteristics, such as presumptuousness on the one hand, or greater or lesser humility on the other, with a view to assessing to what extent any of these factors are useful or otherwise; for example a person with strong self-esteem may certainly be a resource but if that self-esteem is too strong it leads to not viewing others as having something to offer, to looking down at everybody else from a pedestal, then it's not so useful anymore and the same thing is true of humility (D.S.)

Indeed, one of the roles of evaluation is to bring individual characteristics back into equilibrium with the needs of the organizational context, correcting "outsize" behaviours that may not be functional to attaining the work group's objectives and harmful to its internal dynamics. All of the interviewees believed that the evaluator's training was a key aspect, and that if basic training is inadequate, then in-service training becomes of vital importance to those who wish to be professional in conducting evaluations.

As well as the more technical aspects of ongoing training relating to evaluation instruments, new technologies and legislative changes, our informants stressed that it is important for evaluators to undertake a broad and varied range of training courses, which also reflect their own particular learning interests. It is only thus that they can maintain the mental openness and flexibility required to carry out this "impossible" task with rigour and balance. In line with this image of the evaluator, all the participants emphasized that training should be designed to bring about self-development, a wider repertoire of communication and relational techniques, the fine-tuning of observation, listening and counselling skills and the construction of leadership competences, aimed at valuing the resources available within work teams.

In short, the design and implementation of a pilot course for evaluators will allow us to develop these ideas into specific training modules and to test the efficacy of a didactic model based on experiential learning in promoting the emergence and/or reinforcement of these types of knowledge and skills. 


\section{SOCIETY. INTEGRATION. EDUCATION. Volume IV}

\section{Acknowledgments section}

„To the Grundtvig Learning Partnership EduEval project „Evaluation for the Professional Development of Adult Education Staff" supported by the LifeLong Learning Programme of the European Commission.

This learning partnership project has been funded with the support of the European Commission. This communication reflects the views only of the authors, and the Commission cannot be held responsible for any use which may be made of the information contained therein."

\section{References}

Barbier, J. M. (1985), L'évaluation en formation, Paris, Puf.

Benedetti, L., Donati D., Fazioli, R., Maffeo, R. (1997), Valutazione e riforma dei servizi sociali. Qualità, efficienza e privatizzazione, Milano, FrancoAngeli.

Bezzi C. (2001), Il disegno della ricerca valutativa, Milano, FrancoAngeli.

Bezzi C. (2007), Cos'è la valutazione. Un'introduzione ai concetti, le parole chiave e $i$ problemi metodologici, Milano, FrancoAngeli.

W.R. Bion, (1961), Esperienze nei gruppi, trad.it., Roma, Armando,1972.

Buiskool , B.J., \&Broek, S. (2014). Quality in Adult Learning: EU Policies and Shifting Paradigms. In G.K. Zarifis, G.K., \& M.N. Gravani (Eds), Challenging the European Area of Lifelong Learning: A Critical Response), Dordrecht, The Netherlands, Springer Carlsen, pp. 147-156.

Demetrio, D. (1992), Micropedagogia, Firenze, La Nuova Italia.

De Natale, M.L.(2006),La prospettiva dell'educazione permanente, in Vico,G. (Ed), Pedagogia generale e filosofia dell'educazione.Seminariitinerant interuniversitari di filosofia dell'educazione, Milano, Vita \& Pensiero.

Ferenczi S. (1933), Confusione di lingue tra gli adulti e il bambino. Il linguaggio della tenerezza e il linguaggio della passione in Ferenczi S. (1927-1933), Opere, tr.it., Milano, Cortina, 1989, Vol. IV.

Kaës, R. (2009), Le alleanze inconsce, trad.it., Roma, Borla, 2010.

Kaneklin, C. Valutazione e qualità nei servizi. Valutare il valore del servizio in Regalia C., Bruno A. a cura di (2000), Valutazione e qualità nei servizi. Una sfida attuale per le organizzazioni, Milano, Unicopli.

Klein, M. (1952)Some theorethicalconclusionsregarding the emotional life in the infant in Klein, M., Heimann, P., Isaacs,S., Riviere, J., Developments in Psychoanalysis,London, Hogarth.

Massa, R.(1993), La clinica della formazione, FrancoAngeli, Milano

Mezirow J. (2000), Learning to think like an adult: Core concepts of transformation theory in J. Mezirow et alii, Learning as transformation: critical perspectives on a theory in progress, San Francisco, Jossey-Bass, 3-33.

Orefice, P. (2005) (Ed.), Multieda. Dimensioni dell'educare in età adulta: prospettive di ricerca Napoli, Liguori.

Patton, M.Q. (2010), Developmental Evaluation. Applying Complexity Concepts to Enhance Innovation and Use, London, The Guilford Press.

Reason, P. (ed.) (1995) Participation in Human Inquiry. Sage, London.

Riva, M (2004), Il lavoro pedagogico come ricerca dei significati e ascolto delle emozioni, Guerini, Milano.

Schon, D.A. (1983), trad.it., Il professionista riflessivo. Per una nuova epistemologia della pratica professionale, Dedalo, Bari,1993. 
Tramma, S. (2008). L'educatore imperfetto. Senso e complessità del lavoro educativo, Roma, Carocci.

UlivieriStiozzi, S., (2015), Dalle pratiche di valutazione al valore del lavoro di gruppo nei servizi per minori, in Riva, M.G., Vinci, V. (Ed), La valutazione per pensare il lavoro pedagogico, (to be pubblished).

\section{Website}

Pellerey, M. La competenza tra formazione e autoformazione. Implicazioni teoriche e operative,www.cospesitalia.it, p.7.,11/2/2015

Motschilning, R(2014), Now it's official: investment in Adult Learning pays off, European Infonet Adult Education Link to the study: http://ec.europa.eu/education/library/ study/2013/adult-financing_en.pdf/ Adult Education Survey 2007 and 2011: http:/epp.eurostat.ec.europa.eu/portal/page/portal/microdata/adult_education_survey,12/ 2/2015. 